\title{
Is Colonoscopy Indicated in Young Patients with Hematochezia?
}

\author{
Frederick H. Koh ${ }^{a}$ Aaron Seah ${ }^{\mathrm{b}}$ Dedrick Chan ${ }^{\mathrm{a}}$ Jingyu $\mathrm{Ng}^{\mathrm{a}}$ \\ Ker-Kan Tan ${ }^{a, c}$ \\ a Division of Colorectal Surgery, University Surgical Cluster, National University Health \\ System, ${ }^{b}$ Department of Surgery, Tan Tock Seng Hospital, and ${ }^{\mathrm{C}}$ Department of Surgery, \\ Yong Loo Lin School of Medicine, National University of Singapore, Singapore
}

\section{Keywords}

Screening · Early detection · Early diagnosis - Endoscopic diagnosis · Colorectal neoplasms

\begin{abstract}
Background/Aims: While colonoscopy is indicated in patients $>50$ years old presenting with hematochezia, its role in those $\leq 50$ remains debatable. This study aims to evaluate the role of colonoscopy in patients presenting with hematochezia who are $\leq 50$ years old. Methods: A retrospective review of all patients aged $\leq 50$ years who underwent colonoscopy for hematochezia in 2012 was conducted. Patient demographics, endoscopic details, and histological results were analyzed. Patients were stratified by age to compare differences in outcome. $\boldsymbol{R e}$ sults: A total of 361 patients with a median age of 44 (range, 18-50) years were reviewed. Hemorrhoid ( $n=183,69.6 \%$ ) was the most common etiology. Seventy-two neoplastic polyps were identified in 48 (13.3\%) patients. There was a significantly larger proportion of patients aged $41-50$ years who had neoplastic polyps compared to those aged $\leq 40$ (18.8 vs. $3.8 \%$, $p \leq 0.001) ; 43.8 \%(n=28)$ of the neoplastic polyps found in those aged $41-50$ were proximal to the splenic flexure. The only 2 (0.5\%) patients with malignancy were aged $41-50$ years. Conclusion: Performing colonoscopy in patients presenting with hematochezia should be strongly considered for those aged 41-50 years in view of the significant likelihood of underlying neoplastic polyps compared to those aged $\leq 40$ years.

(C) 2017 S. Karger AG, Basel
\end{abstract}

\section{Introduction}

Hematochezia is defined as frank bleeding per rectum and has a worldwide hospitalization incidence of 36 per 100,000 patients [1,2]. It is the most common presentation of colorectal cancer and is encountered in $25.5-42.3 \%$ of the patients $[3,4]$. As most of the 
colorectal cancers arise from the adenoma-carcinoma pathway, it is vital to remove any neoplastic polyp prior to malignant transformation.

While colonoscopy is clearly indicated in patients aged $>50$ years old presenting with hematochezia, its role in those $\leq 50$ years old remains debatable. The reported incidence of colorectal cancer in this group of patients is exceedingly low $[5,6]$. Although flexible sigmoidoscopy has been advocated in these patients, the risk of missing neoplastic lesions in the proximal part of the colon is present. This is perhaps more pertinent in Asians where colon cancers are seen in higher frequency in the right colon and in younger patients [7].

Thus, the aim of this study was to evaluate the role of colonoscopy in patients $\leq 50$ years old presenting with the primary symptom of hematochezia.

\section{Methods}

NHG Domain Specific Review Board approval was obtained, and a retrospective review of all patients $\leq 50$ years old who underwent colonoscopy for the primary symptom of hematochezia from a single institution in 2012 was performed. Hematochezia was defined as the passage of fresh blood per rectum with or without stools. Only patients aged 18-50 years old were included, and the list of patients was retrieved using our institution's endoscopic database. Data collected included patient demographics, likely cause of bleeding, site of pathology, location of any polyps, and their histological diagnoses. Incidental polyp was defined as polyps identified during colonoscopic examination which were not responsible for the hematochezia. Neoplastic polyp was defined as tubular or tubulovillous adenoma on histological examination. Patients were also stratified into age groups for subsequent analysis.

All colonoscopies in our institution were performed by gastroenterologists or general surgeons of at least the Registrar/Senior Resident level. All patients underwent appropriate preprocedural bowel preparation before the colonoscopy. The decision to administer moderate sedation is left at the discretion of the endoscopist. All colonoscopies begin in the left lateral position with regular blood pressure, heart rate, and oxygen saturation monitoring. All findings were documented based on its entity, location, size, and likely pathology. Narrow band imaging was available and may have been used, but this was unfortunately not captured in the final endoscopy report. If feasible and safe, all neoplastic lesions were removed for histological analysis during the colonoscopy, and the patients were followed-up in the outpatient clinic for subsequent management.

Statistical analysis was performed using Pearson's $\chi^{2}$ for categorical analysis, and all analyses were performed using IBM SPSS version 20 (SPSS, Chicago, IL, USA).

\section{Results}

A total of 361 patients, with a median age of 44 (range, 18-50) years old, underwent colonoscopy for the primary symptom of hematochezia during the study period. The likely etiology of the hematochezia was identified in 263 (72.9\%) patients, with hemorrhoids being the most common diagnosis seen in $183(69.6 \%)$ patients. The cause of bleeding was not clearly demonstrated in $98(27.1 \%)$ patients. Table 1 illustrates the patient demographics and pathologies identified.

During the colonoscopic examination, a total of 114 polyps were identified in $78(21.6 \%)$ patients. Histopathological report revealed that 72 of the polyps were neoplastic in 48 $(13.3 \%)$ patients. Almost half $(n=31,43.1 \%)$ of these polyps located proximal to the splenic flexure. Two $(0.5 \%)$ patients were diagnosed with colorectal adenocarcinoma and subsequently underwent cancer staging and were treated accordingly. Table 2 provides the details of the polyps identified during colonoscopy.

After stratification, there was a significantly higher proportion of patients aged 41-50 years which were found to have neoplastic polyps compared to the group aged $\leq 40$ (18.8 vs. 
Table 1. Demographics and details of endoscopic evaluation

\begin{tabular}{lcccc}
\hline Variables & \multicolumn{2}{l}{ Frequency, $n$ (\%) } & \multirow{2}{*}{$p$ value } \\
\cline { 2 - 3 } & study population & $\leq 40$ years old & $41-50$ years old & \\
\hline Total & 361 & $132(36.6)$ & $229(63.4)$ & - \\
Gender & & & & 0.257 \\
$\quad$ Male & $237(65.7)$ & $90(68.2)$ & $147(64.2)$ & \\
$\quad$ Female & $124(34.3)$ & $42(31.8)$ & $82(35.8)$ & \\
Median age (range), years & $44(18-50)$ & - & & \\
Identified etiology of hematochezia & $263(72.9)$ & $93(70.5)$ & $170(74.2)$ & 0.255 \\
$\quad$ Hemorrhoids & $183(69.6)$ & $63(67.7)$ & $120(70.6)$ & 0.228 \\
$\quad$ Polyp(s) & $29(11.0)$ & $3(3.2)$ & $26(15.3)$ & 0.001 \\
$\quad$ Diverticular disease & $8(3.0)$ & $1(1.1)$ & $7(4.1)$ & 0.144 \\
$\quad$ Colorectal cancer & $2(0.8)$ & 0 & $2(1.2)$ & 0.402 \\
$\quad$ Sigmoid & $1(50.0)$ & & $1(50.0)$ & \\
$\quad$ Rectum & $1(50.0)$ & & $1(50.0)$ & 0.060 \\
$\quad$ Colitis & $11(4.2)$ & $7(7.5)$ & $4(2.4)$ & - \\
$\quad$ Others & $30(11.4)$ & $19(20.4)$ & $11(6.5)$ & \\
\hline
\end{tabular}

Table 2. Polyp identification rate

\begin{tabular}{|c|c|c|c|c|}
\hline \multirow[t]{2}{*}{ Variables } & \multicolumn{3}{|c|}{ Frequency, $n(\%)$} & \multirow[t]{2}{*}{$p$ value } \\
\hline & $\begin{array}{l}\text { study } \\
\text { population }\end{array}$ & $\begin{array}{l}\leq 40 \text { years } \\
\text { old }\end{array}$ & $\begin{array}{l}41-50 \text { years } \\
\text { old }\end{array}$ & \\
\hline Total polyps identified & 114 & 20 & 94 & - \\
\hline Patients with polyps & $78(21.6)$ & $13(9.8)$ & $65(28.4)$ & $<0.001$ \\
\hline Patients with incidental polyps & $57(15.8)$ & $11(8.3)$ & $46(20.1)$ & 0.003 \\
\hline Diminutive $(\leq 4 \mathrm{~mm})$ & 56 & 7 & 49 & \\
\hline Small $(4-10 \mathrm{~mm})$ & 37 & 9 & 28 & \\
\hline Large $(>10 \mathrm{~mm})$ & 2 & 2 & 0 & \\
\hline Patients with neoplastic polyps & $48(13.3)$ & $5(3.8)$ & $43(18.8)$ & $<0.001$ \\
\hline Diminutive $(\leq 4 \mathrm{~mm})$ & 50 & 2 & 48 & \\
\hline Small $(4-10 \mathrm{~mm})$ & 8 & 2 & 6 & \\
\hline Large $(>10 \mathrm{~mm})$ & 7 & 1 & 6 & \\
\hline Sites of neoplastic lesions stratified by age & - & & & - \\
\hline Colorectal cancer & & 0 & 2 & \\
\hline Neoplastic polyp & & 9 & 64 & \\
\hline Caecum & & 0 & 7 (10.9) & \\
\hline Ascending colon & & $3(37.5)$ & $10(15.6)$ & \\
\hline Hepatic flexure & & 0 & $4(6.3)$ & \\
\hline Transverse colon & & 0 & $7(10.9)$ & \\
\hline Splenic flexure & & 0 & $1(1.6)$ & \\
\hline Descending colon & & 0 & 7 (10.9) & \\
\hline Sigmoid colon & & $5(62.5)$ & $17(26.6)$ & \\
\hline Rectum & & 0 & $11(17.2)$ & \\
\hline
\end{tabular}

$3.8 \%, p<0.001)$. There was also more large neoplastic polyps identified in patients aged 41-50 compared to those $\leq 40$ ( 6 vs. $1, p=0.49$ ). Perhaps more importantly, there was a higher proportion of right-sided lesions in the group aged 41-50 years compared to that aged $\leq 40$ years, although the difference did not reach statistical significance ( $45.8 \mathrm{vs.} 37.5 \%$, $p=0.74)$. 
There was no significant periprocedural complication such as unplanned readmission, perforation, or significant bleeding documented.

\section{Discussion}

Colon cancer is the number one malignancy in Singapore [8]. More worryingly, its incidence in those $\leq 50$ years of age has been increasing with the increased use of endoscopic evaluation [9-11]. In Singapore, the incidence of colorectal cancer was 22.5 per 100,000 per year for males between 40 and 49 years old and 20 per 100,000 per year for females of the same age group during the years 2010-2014 [8].

There have been numerous studies in the literature which have attempted to address the use of endoscopic evaluation for patients $\leq 50$ years of age. Many of these studies revealed that up to $15 \%$ of these patients, who presented for hematochezia, were found to have neoplastic lesions on full colonoscopic examination and thus were recommended full colonoscopic evaluation [5,12]. More recent studies further stratified the endoscopic findings of patients $\leq 50$ years old presenting with hematochezia. These studies revealed that these patients who are $<40$ years old have endoscopic lesions found mainly in the distal colon $[13,14]$.

Our study shows concurrence to the literature in that $\geq 1$ in 10 of our patients presenting with hematochezia, who were $\leq 50$ years of age, had neoplastic lesions. Although we believe that the majority of these neoplastic polyps would not have accounted for the presentation, the removal of these neoplastic polyps would negate the risks of developing colorectal cancer, especially since the majority of colorectal cancers still develop via the adenoma-carcinoma pathway.

It is perhaps more important to highlight that 1 in every 5.4 colonoscopies performed in the group aged 41-50 identified a neoplastic polyp. This is in comparison to 1 in every 26.4 colonoscopies in those aged $\leq 40$, with all 3 polyps arising from the ascending colon having a histology of tubular adenoma with only low-grade dysplasia. Combined with the findings that almost half (47.8\%) of the neoplastic lesions found in patients between the age of 41 and 50 years were located proximal to the splenic flexure, we believe that a full colonoscopy should at least be advocated in patients aged 41-50 years who present with hematochezia, even though the polyps may not be the cause of the bleeding, which may help to reduce the risk of developing cancer. These findings are consistent with the observation that cancers arising proximal to the splenic flexure occurred more frequently than in the Western population [15].

From a colorectal cancer screening perspective, it is perhaps important to advocate colonoscopy in patients aged between 41 and 50 years. A recent study from our local population stated that the uptake of colorectal cancer screening in the population who fulfilled the screening criteria was only $26.7 \%$, with a majority of them undergoing fecal occult blood tests [16]. Many of these patients declined screening due to various reasons, and interestingly, cost was not one of them. This is likely due to the subsidy given by the government in our country. Thus, advocating colonoscopy in these patients serves 2 purposes, not only would the procedure identify and remove neoplastic polyps in approximately $20 \%$ of the patients, it would also prevent false reassurance to these patients given that the majority of them are unlikely to proceed with screening for colorectal cancer from 50 years old onwards if they remained asymptomatic. In addition, performing a colonoscopy earlier for those presenting with lower gastrointestinal symptoms may also improve the identification of familial polyposis syndromes or Lynch syndrome, which will be beneficial not just to the patients but their families as well. 
Current guidelines proposed by the American Society of Gastroenterology (ASGE) state that colonoscopy should be performed in patients aged $>50$ years old who present with hematochezia, while flexible sigmoidoscopy would suffice in young healthy patients aged $\leq 40$ years old [17]. The guidelines also recommended that those $\leq 40$ years without a definitive source of bleed on flexible sigmoidoscopy or those with alarm symptoms should proceed to full colonoscopic examination. While the authors concurred with the guidelines as only less than $5 \%$ of the patients aged $\leq 40$ had a neoplastic lesion, with the majority of them found distal to the splenic flexure, we would highlight that almost 1 in 5 of those aged 41-50 years had neoplastic polyps, almost half being proximal to the splenic flexure, despite more than $70 \%$ of them having a definitive source of bleeding. Thus, clinicians should have a much lower threshold of recommended colonoscopy from the onset for those aged 41-50 years compared to those aged $\leq 40$ years.

Colonoscopy is not without its own set of complications. Albeit exceedingly rare and not seen in our group of patients, the impact of perforation and bleeding can be considerable [18, 19]. Apart from direct complications, other issues surrounding a colonoscopy include the need for a thorough bowel preparation and the risk of moderate sedation.

Any retrospective study is fraught with several limitations. We were unable to review whether patients had underlying personal or family history, which might have affected their risk of developing colorectal malignancy, nor evaluate better the extent of their symptoms prior to presentation. Hematological assessment like hemoglobin level was not available either. The selection criteria for patients aged $\leq 50$ to undergo colonoscopy were left to the discretion of the attending physician. There would have been patients who have not been advised or refused to undergo colonoscopy or simply had a flexible sigmoidoscopy performed. The experience of the endoscopist and the thoroughness of the colonoscopy in ensuring all neoplastic lesions have been identified, were also not standardized, although our institution has a stringent accreditation process to ensure that only experienced endoscopists of at least Registrar/Senior Resident qualification are allowed to perform the procedure independently. Taking all these into consideration, the proportion of patients with neoplastic lesions can only be higher, which would only add support to our recommendation that colonoscopy should be performed in all patients aged $\leq 50$ years old presenting with the primary symptom of hematochezia.

\section{Conclusions}

Clinicians should have a lower threshold for recommending colonoscopy to patients aged between 41 and 50 years old presenting with hematochezia as the incidence of neoplastic polyps in these individuals is approximately $20 \%$. Flexible sigmoidoscopy is perhaps sufficient for those aged $\leq 40$ years.

\section{Disclosure Statement}

The authors declare that they have no conflicts of interest. 


\section{References}

1 Ghassemi KA, Jensen DM: Lower GI bleeding: epidemiology and management. Curr Gastroenterol Rep 2013; $15: 333$.

2 Eckardt VF, Schmitt T, Kanzler G, et al: Does scant hematochezia necessitate the performance of total colonoscopy? Endoscopy 2002;34:599-603.

3 Hsiang JC, Bai W, Lal D: Symptom presentations and other characteristics of colorectal cancer patients and the diagnostic performance of the Auckland Regional Grading Criteria for Suspected Colorectal Cancer in the South Auckland population. N Z Med J 2013;126:95-107.

4 Koo HY, Park KJ, Oh JH, et al: Investigation of clinical manifestations in Korean colorectal cancer patients. Ann Coloproctol 2013;29:139-143.

5 Wong RF, Khosla R, Moore JH, et al: Consider colonoscopy for young patients with hematochezia. J Fam Pract 2004;53:879-884.

6 Marderstein EL, Church JM: Classic "outlet" rectal bleeding does not require full colonoscopy to exclude significant pathology. Dis Colon Rectum 2008;51:202-206.

7 Yeo SA, Chew MH, Koh PK, et al: Young colorectal carcinoma patients do not have a poorer prognosis: a comparative review of 2,426 cases. Tech Coloproctol 2013;17:653-661.

8 Singapore Cancer Registry, Annual Registry Report: Trends in Cancer Incidence in Singapore 2010-2014.

9 O’Connell JB, Maggard MA, Liu JH, Etzioni DA, Livingston EH, Ko CY: Rates of colon and rectal cancers are increasing in young adults. Am Surg 2003;69:866-872.

10 Amri R, Bordeianou LG, Berger DL: The conundrum of the young colon cancer patient. Surgery 2015;158: 1696-1703.

11 Steele SR, Park GE, Johnson EK, Martin MJ, Stojadinovic A, Maykel JA, Causey MW: The impact of age on colorectal cancer incidence, treatment, and outcomes in an equal-access health care system. Dis Colon Rectum 2014;57:303-310.

12 Nikpour S, Ali Asgari A: Colonoscopic evaluation of minimal rectal bleeding in average-risk patients for colorectal cancer. World J Gastroenterol 2008;14:6536-6540.

13 Khalid AB, Majid S, Salih M, Hashmat F, Jafri W: Is full colonoscopic examination necessary in young patients with fresh bleeding per rectum? Endoscopy 2011;43:692-696.

14 Barret M, Coriat R, Lecler A, Deyra J, Prat F, Chaussade S: Flexible sigmoidoscopy: an archaic tool for 40-50year-old patients with fresh bleeding per rectum. Endoscopy 2012;44:217.

15 Nikpour S, Ali Asgari A: Colonoscopic evaluation of minimal rectal bleeding in average-risk patients for colorectal cancer. World J Gastroenterol 2008;14:6536-6540.

16 Wong RK, Wong ML, Chan YH, et al: Gender differences in predictors of colorectal cancer screening uptake: a national cross sectional study based on the health belief model. BMC Public Health 2013;13:677.

17 ASGE Standards of Practice Committee, Pasha SF, Shergill A, Acosta RD, Chandrasekhara V, Chathadi KV, Early D, Evans JA, Fisher D, Fonkalsrud L, Hwang JH, Khashab MA, Lightdale JR, Muthusamy VR, Saltzman JR, Cash BD: The role of endoscopy in the patient with lower GI bleeding. Gastrointest Endosc 2014;79:875-885.

18 Anderson ML, Pasha TM, Leighton JA: Endoscopic perforation of the colon: lessons from a 10-year study. Am J Gastroenterol 2000;95:3418-3422.

19 Atkin WS, Hart A, Edwards R, et al: Uptake, yield of neoplasia, and adverse effects of flexible sigmoidoscopy screening. Gut 1998;42:560-565. 